\title{
Bone: Silk, metal and bone: why take implants out?
}

Per Aspenberg

\section{Linköping University Post Print}

\section{Tweet}

N.B.: When citing this work, cite the original article.

Original Publication:

Per Aspenberg , Bone: Silk, metal and bone: why take implants out?, 2014, Nature Reviews Rheumatology, (10), 7, 386-387.

http://dx.doi.org/10.1038/nrrheum.2014.57

Copyright: Nature Publishing Group

http://www.nature.com/

Postprint available at: Linköping University Electronic Press

http://urn.kb.se/resolve?urn=urn:nbn:se:liu:diva-109240 


\section{BONE}

\section{Silk, metal and bone: why take implants out?}

\section{Per Aspenberg}

\section{Standfirst}

Degradable screws and plates for bone surgery have been produced from silk protein. The idea is to eliminate the need to take the implant out when the bone has healed. Will they provide sufficient strength, and will they degrade without a disturbing inflammation? And why take implants out in the first place?

Aspenberg, P. Nat. Rev. Rheumatol. advance online publication 2014

Fractured bones normally heal spontaneously, but to ensure that they heal in a correct position, they are often fixed with metal nails, screws or plates. These implants are often removed by a new operation when the fracture is healed. In an article published in Nature Communications, Perrone et al. presented for the first time a solid, machinable material made of silk protein. ${ }^{1}$ They manufactured selftapping screws that could be inserted in bone and degraded slowly over time. The ability to degrade would eliminate the need for surgical removal of the implant. The material seemed to soften and swell with hydration, which is an obvious problem. The study authors implanted silk screws in intact rat femora, and measured the force needed to pull them out after 4 and 8 weeks. This force reflects the strength of the new bone that has formed within the screw threads. For the silk screws, it amounted to less than one-third of that reported for similar-sized metal screws in rat tibiae, ${ }^{2}$ but this finding might be explained by differences in study design. Histological analysis of the implant site showed degradation of the implant surface and giant cells, possibly indicating a foreign body reaction, together with bone formation. Obviously, more work is needed before it can be concluded for what purpose this material might become useful in bone surgery.

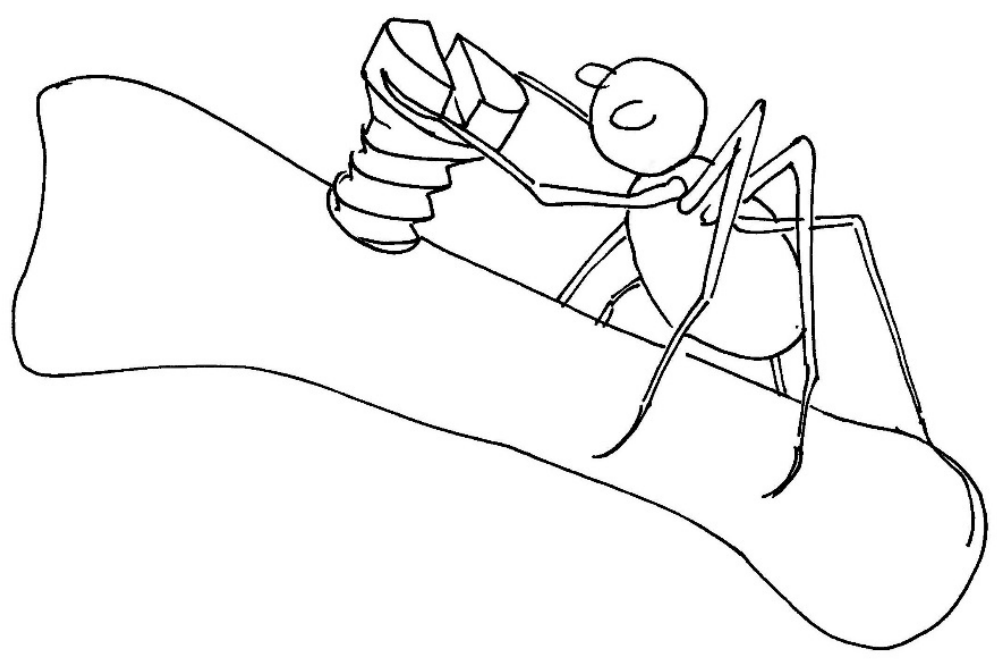

Removal of fracture fixation implants after healing is a surgical operation not without risk. Avoiding such surgery has been a main rationale for development of degradable implants. Degradable implants made of different polylactic-glycolic acids have been available for decades, but gained limited popularity. The main improvement with the new silk material would be that it can be machined to 
form more precisely shaped devices, and sterilized by autoclaving. Furthermore, the degradation of polylactic-glycolic acid implants is associated with local inflammation and sometimes sinus formation in the bone that can be detrimental. ${ }^{3,4}$ Perrone et al. hope that this issue will be less of a problem with silk.

Removal of internal fracture fixation devices can be common, but it is unclear how often it is necessary. Any surgery should have a clear motivation, but for implant removal the underlying reasoning behind the procedure is often simply that the implant is in there and so must be taken out. If implant retainment is not associated with any risk or discomfort, this reason for removal is irrational. Such irrationality is not uncommon: benign cavities in bone are often treated with unnecessary void fillers, as a result of some kind of orthopaedic 'horror vacui'. ${ }^{5}$ Similarly, there might be an orthopaedic 'xenophobia' behind unnecessary removal of foreign materials. Interestingly, implant retainment is not regarded as a problem in the context of total joint replacements (and who would like to have a degradable hip replacement?)

Perrone et al. ${ }^{1}$ argue that metal implants need removal because of stress shielding, which relates to removal of mechanical loading of the bone adjacent to the implant as a result of its placement, and subsequent bone resorption in that area due to lack of mechanical stimulation. Stress shielding under metal plates has previously been thought to necessitate early removal of the plate or the use of less stiff materials. However, the bone changes observed under metal plates seem to be caused by surgical devascularization during the implantation procedure. ${ }^{6}$ With less traumatic surgery and plates designed to cause less disturbance of the vascular supply to the bone, the problems ascribed to stress shielding have largely disappeared. ${ }^{6}$ Regardless of the design of fracture fixation devices, the bone normally seems to be sufficiently loaded to maintain itself. ${ }^{7}$

When implants really need to be removed, it is almost exclusively because they protrude out of the bone and cause discomfort, for example at the tibial tuberosity when kneeling. Plates can also interfere with tendons gliding over them, causing local inflammation, and such complications might necessitate implant removal. However, if these implants were instead degradable, the inflammation associated with degradation might even cause worse local problems. For instance, the new silk material is degraded enzymatically, and histological analysis demonstrated formation of fragments and particles at the surface ${ }^{1}$. Phagocytosable particles tend to cause inflammation, even if the material is biocompatible in bulk form. This process can reduce formation and increase resorption of bone, which might explain the low pull-out force of the silk screws. As metal implants cause minor issues, it is imperative that a solution to these issues doesn't itself cause further problems.

Implant removal is surprisingly common. In Sweden, 37,000 adult patients received metal fracture fixation implants in 2011, and 13,000 underwent implant removal. The number of adults undergoing fracture surgery in Sweden increased from 2005 to 2011 by $20 \%$, but removals increased by $35 \%{ }^{8}$ The highest rate of removal (70\%) was reported for the ankle and foot. Ligamentous healing and adaptation after an ankle fracture can take years, and symptoms can be erroneously ascribed to remaining, palpable implants. Removal rates might also be influenced by economic incitements. Still, in many cases, the reason can just be tradition. In children, metal implants are routinely removed, although it can often be unnecessary. ${ }^{9,10}$ In many cases, a retained implant would be hidden inside the larger bone eventually formed by growth. An argument put forward for implant removal in children is that an implant left behind from young age might interfere with fracture surgery later in life. Children are exposed to surgery just to reduce possible technical problems in the unlikely event that the same bone needs surgery in adulthood! 
Implants for fracture fixation sometimes do need to be removed, and a perfect implant therefore would maintain strength until the fracture is healed, and then disappear quickly without substantial local inflammation. Unfortunately, an implant that is required to remain intact for months would probably take years to disappear. Situations do, however, exist (for example, in the treatment of ankle fractures) in which screws are expected to hold only for the short time needed for soft tissue healing and then loosen their grip to enable small motions. Silk screws might become a practical possibility in this scenario. Crucially, this new material ${ }^{1}$ might enable applications we have not yet thought of and future experimentation is warranted. However, degradation of implants might sometimes cause problems related to inflammation, metal implants work well, and unnecessary removal of metal implants might be a greater issue than implant retainment.

1. Perrone, G.S. et al. The use of silk-based devices for fracture fixation. Nat Commun 5, 3385 (2014).

2. Wermelin, K., Tengvall, P. \& Aspenberg, P. Surface-bound bisphosphonates enhance screw fixation in rats--increasing effect up to 8 weeks after insertion. Acta Orthop 78, 385-92 (2007).

3. Ambrose, C.G. \& Clanton, T.O. Bioabsorbable implants: review of clinical experience in orthopedic surgery. Ann Biomed Eng 32, 171-7 (2004).

4. Bostman, O.M. \& Pihlajamaki, H.K. Adverse tissue reactions to bioabsorbable fixation devices. Clin Orthop Relat Res, 216-27 (2000).

5. Aspenberg, P. Black holes in bone - irresistible attractors of foreign materials? Acta Orthop 80, 2-3 (2009).

6. Perren, S.M. Evolution of the internal fixation of long bone fractures. J Bone Joint Surg [Br] 84-B,1093-110 (2002).

7. Cordey, J., Perren, S.M. \& Steinemann, S.G. Stress protection due to plates: myth or reality? A parametric analysis made using the composite beam theory. Injury 31 Suppl 3, C1-13 (2000).

8. Socialstyrelsen. ( http://www.socialstyrelsen.se/statistik/statistikdatabas, 2014).

9. Vopat, B., Kane, P., Fitzgibbons, P., Got, C. \& Katarincic, J. Complications Associated with Retained Implants After Plate Fixation of the Pediatric Forearm. J Orthop Trauma (2013).

10. May, C. et al. Complications of plate fixation of femoral shaft fractures in children and adolescents. J Child Orthop 7, 235-43 (2013).

\section{Biography}

Per Aspenberg, MD, $\mathrm{PhD}$, trained in Lund, Sweden, and is professor of Orthopaedic surgery in Linköping since 2001. His research involves animal experimentation and clinical studies regarding implant fixation, fracture and tendon healing, and the effects of mechanical loading and various drugs on these processes. He has demonstrated improved fixation of total joint replacements and dental fixtures through local application of bisphosphonates in academic randomized trials. 